\title{
Distinguishing between household headship with and without power and its association with subjective well-being among older adults: an analytical cross- sectional study in India
}

\author{
Shobhit Srivastava ${ }^{1}$ (D, S. K. Singh ${ }^{2}$ (D) Manish $\operatorname{Kumar}^{1}$ and T. Muhammad ${ }^{1 *}$ (D)
}

\begin{abstract}
Background: The status of household headship accorded to the older members of the family is often symbolic and seldom vested with some control over resources. The increased dependency and diminished ability to contribute to household economy are major factors that lead to a decline in the respect accorded to older people and their status in the family. The present study aimed to understand the distinction between the functional and nominal household headship status of older adults based on their decision-making power and examine how it is associated with their subjective well-being.
\end{abstract}

Method: The present research used data from the 'Building a Knowledge Base on Population Aging in India' (BKPAl) which is nationally representative. The survey was conducted in 2011, across seven states of India. Descriptive statistics along with percentage distribution were calculated for subjective well-being over explanatory variables. For finding the association between subjective well-being over explanatory variables, binary logistic regression model was used.

Results: The mean age of the study population was 68 years [Cl: 67.8-68.2]. About $5 \%$ of older adults had nominal while $95 \%$ had functional headship status. The prevalence of low subjective well-being (LSWB) was significantly higher among older adults with nominal headship status (58\%) than functional headship status (23\%). After controlling for several other variables, older adults with nominal headship status were $59 \%$ significantly more likely to have low subjective well-being than individuals with functional headship status (OR $=1.59 ; 95 \%$ Cl: 1.10, 2.31). Further, older adults with psychological distress, chronic morbidity, poor self-reported health, no community involvement and no one to trust on were at higher risk of LSWB than their counterparts.

\footnotetext{
* Correspondence: muhammad@iips.net

'Department of Mathematical Demography and Statistics, International Institute for Population Sciences, Mumbai, Maharashtra 400088, India

Full list of author information is available at the end of the article
}

(c) The Author(s). 2021 Open Access This article is licensed under a Creative Commons Attribution 4.0 International License, which permits use, sharing, adaptation, distribution and reproduction in any medium or format, as long as you give appropriate credit to the original author(s) and the source, provide a link to the Creative Commons licence, and indicate if changes were made. The images or other third party material in this article are included in the article's Creative Commons licence, unless indicated otherwise in a credit line to the material. If material is not included in the article's Creative Commons licence and your intended use is not permitted by statutory regulation or exceeds the permitted use, you will need to obtain permission directly from the copyright holder. To view a copy of this licence, visit http://creativecommons.org/licenses/by/4.0/. The Creative Commons Public Domain Dedication waiver (http://creativecommons.org/publicdomain/zero/1.0/) applies to the data made available in this article, unless otherwise stated in a credit line to the data. 
(Continued from previous page)

Conclusions: Findings suggest that older adults who do not have a household headship with power with active participation in household decision-making as well as those who have no involvement in social activities or have poor health conditions need to be given more attention. Thus, to keep a large proportion of older population gainfully engaged, their care and support should be ensured via providing appropriate services that would enhance their roles and responsibilities and overall wellbeing.

Keywords: Household headship, Subjective wellbeing, Older adults, India

\section{Introduction}

According to census 2011, In India, $8 \%$ of the total population were above the age of 60 years [1], and as per the estimates prepared by United Nations, it is likely to rise to $19 \%$ by 2050 [2]. Among a rapidly growing older population, a multitude of resource constraints contributes to loss of self-esteem and adverse psychological effects [3]. In the South Asian settings where family ties are considered paramount, intergenerational conflicts may have negative consequences on the well-being of older individuals [4].

The status of household headship accorded to the older members of the Indian families which is often symbolic and seldom vested with some control over resources is ambivalent in the existing literature. Study shows that increased dependency and diminished ability to contribute to household economy were found as major factors that lead to a decline in the respect accorded to older people and their status in the family [5]. While grown-up children tend to make decisions as they become the main breadwinners in the household, the decision-making power of older persons in India has been declining [6]. It is found that although they own private assets and share the same amount of intrahousehold transfers, older adults who reside with young and adult children were less likely to be household heads than were those with spouses and grandchildren [7]. Nevertheless, older adults often tend to maintain some control over their resources to prevent themselves from feeling like a burden to the family members and to retain children's respect [8]. For this cause, they may actively involve in household decision-making and try to establish themselves as independent heads of the household [9].

As evidence suggests, if older individuals consider themselves as the household heads and their adult children stop taking their opinion into account for important household decisions, it can negatively affect their mental well-being [10]. Similarly, functional capacities are recognized as being shaped by class, gender, and other factors and functional old age can be delayed through the provision of adequate care and support [11, 12]. On the other hand, older adults depending on their children or family members to look after them who often consider them as a burden may result in illtreatment and a multitude of health issues [13, 14]. Also, older members who take on fewer and lighter domestic duties, gain respect but experience a decline in their tangible household political and economic powers [15]. Hence, those older individuals who withdraw from active engagement in household activities after reaching a particular age are considered as transitioning from household headship to merely a senior member in the household and eventually giving up the material pleasure in their lifecycle [16]. Notably, evidence suggests that in order to promote active engagement of older adults, there is a need for an increased sense of coherence and personal autonomy [10, 17]. Thus, despite satisfaction with participation being a challenge to successful aging of the older population, it can also be a distinctive factor of actual participation and the quality of participation [18].

Furthermore, normal functioning that includes involvement in daily household activities is crucial to the well-being of older adults [16]. And with increased age, the likelihood that a person aged 60 and older will head his or her household increases [19]. However, the linkage between perceived statuses and functional support that is actually provided has been examined with less care. Besides, a headship status representing members' shared interests is regarded as inadequate and inappropriate when it is automatically ascribed to the senior male' [20]. Even though, when the value system becomes stronger and actual receipt of social supports are ensured, people generally become satisfied in old age and experience relatively high levels of emotional well-being [21]. Further, studies found gender differences in personal significance that a person attributes to the roles he or she occupies and the satisfaction from such rolemaking varies by its meanings [22]. Hence, with an unprecedented increase in the proportion of population over age 60 years in India that is expected to rise to nearly $20 \%$ by the year 2050 [23], it is important to better understand the conditions under which wellbeing of older adults can be ensured.

In this regard, we hypothesize that older adults who reported having a role in household decision-making were more likely to functionally head their households 
than their counterparts who often remain heads without any role-making. And the present study attempts to fill in a gap in well-being research in India by accessing data that explicitly have asked questions concerning decisionmaking in the household and examining the distinction between the functional and nominal household headship status of older adults based on their decision making power and how it is associated with their subjective well-being.

\section{Methods}

\section{Data}

The present research used data from Building a Knowledge Base on Population Aging in India (BKPAI) which is nationally representative. The survey was conducted in 2011, across seven states of India. The survey was sponsored by the Institute for Social and Economic Change (ISEC), Bangalore, Institute for economic growth (IEG), Delhi, Tata Institute for Social Sciences (TISS), Mumbai, and United Nations Population Fund (UNFPA), New Delhi [24]. The survey gathered information on various socio-economic, demographic, and health aspects of aging among households of those aged 60 years and above. The data from all the seven states were collected which represents the four regions of India. The states of Punjab and Himachal represent the northern part, West Bengal and Orissa represent the eastern part, Tamil Nadu and Kerala represent the southern part, and Maharashtra represents the western part of the country. The urban and rural samples within each state were drawn separately. The PSUs in the rural areas were villages, whereas the urban wards were the PSUs in the urban areas. First, villages were classified into different strata based on population size, and the number of PSUs to be selected was determined in proportion to the population size of each stratum. Using probability proportional to population size (PPS) technique, the primary sampling units (PSUs) were selected and within each selected PSU, elderly households were selected through systematic sampling [24]. A similar procedure was applied in drawing samples from urban areas. However, a total of 8329 households were interviewed and among them, 9852 older adults' interviews were conducted [24]. The study only included those older adults who were the head of the households i.e. the effective sample size for the study was 4604 older adults.

\section{Variable description Outcome variable}

The outcome variable was subjective well-being among older adults. Nine questions were asked to assess this variable which includes a. Feels like life is interesting b. Compared with the past, it feels like present life is better c. On the whole, how happy with the kind of things doing in recent year's d. Achieved the standard of living and the social status in life as expected e. The extent to which have achieved success and getting ahead f. Feels like normally accomplished whatever wanted to accomplish g. Feels like it is able to manage situations even when they do not turn out to be as expected h. Feels like confident that in case of crisis (anything that substantially upsets the situation in life), will be able to handle it or face it boldly i. With the things going on now, feel confident in coping with the future. The responses were 1 "Most of the time", 2 "Sometimes", and 3 "Hardly ever". The responses were coded as 0 "most of the time/ sometime" and 1 "hardly ever". A scale of 0-9 was then generated using egen command in Stata-14 and was categorized as 0 "high" experiencing better experience (representing 6+ scores) and 1 "low" experiencing negative experience (representing score 5 and less) (Cronbach alpha: 0.89) $[14,25,26]$.

\section{Explanatory variable}

1. The main explanatory variable was headship status among older adults i.e. whether the status was nominal or functional. The nominal headship was defined as the head who does not have any decision-making power in the household whereas the functional head was the head who has the absolute/partial power to make household decisions. The variable was generated using two variables i.e. first whether the older adult is the head of the household or not and whether he makes the major household decision or not. The sample only includes the older adults who were the heads of the household. The decision-making power was assessed using six questions which include "Who usually makes the following decisions: you alone or with your spouse, with your children, or with others?" on the following issues (a). Marriage of son/daughter. (b). Buying and selling of property (c). buying other household items (d). Gifts to daughters, grandchildren, other relatives (e). Education of children, grandchildren (f). arrangement of social and religious events (Cronbach alpha: 0.88). The responses were coded as 0 "no role in decision making" and 1 "full/partial role in decision making" i.e. decide alone or with your spouse, with your children, or with others. Headship status was coded as 0 "nominal head" which combines head with no role as decision-maker in the household and 1 "functional head" which combines head with full/ partial role in decision-maker in the household.

2. Age was recoded as $60-69,70-79$, and $80+$ years.

3. Sex was recoded as male and female. 
4. Educational status was recoded as no schooling, below 5 years of schooling, $6-10$ years of schooling, and 11 and above years of schooling [14].

5. Marital status was recoded as currently in union and not in union "included never married, widowed, divorced and separated".

6. Co-residing with children was coded as "no" and "yes"

7. Working status was recoded as "working", "not working" and "retired". The status was for the last year [27].

8. Community involvement was generated using the following question a. attended a public meeting in the last 11 months with a discussion on local, community, or political affairs, b. Have attended any group, club, society, union, or organizational meeting in last 11 months, c. Have worked with other people in the neighbourhood to fix or improve something in the last 11 months, d. Have attended or participated in any religious programs/ services etc. (not including weddings and funerals) in the last 11 months, and e. Have gone out of the house to visit friends or relatives in the last 11 months. The responses were never, rarely, occasionally, and frequently. They were coded as 0 "never" and 1 "rarely/occasionally/frequently" A scale of $0-5$ was generated and was coded as 0 "no community involvement" and 1-4 were coded as 1 "community involvement" [28].

9. Trust over someone was assessed using the question "do you have someone you can trust and confide in?" which was recoded as 0 "yes" and 1 "no" [28].

10. Self-rated health had a scale of 1 to 5 "poor to excellent" and was recoded as 0 "good" (representing good, very good, and excellent) and 1 "poor" (representing poor or fair) [29].

11. Psychological distress was having a scale of 0 to 12 based on experiencing stressful symptoms and was recoded as 1 "high" (representing 6+ scores) and 0 "low" (representing score 5 and less) (Cronbach alpha: 0.90) [14, 25, 28]. The variable was coded using 12 questions namely a. Recently able to concentrate on whatever doing $b$. Recently lost much sleep due to some worry c. Recently felt constantly under strain d. Recently felt like couldn't overcome difficulties e. Recently been feeling unhappy and depressed f. Recently been losing self-confidence g. Recently been thinking self as a worthless person h. Recently felt like playing a useful role in life i. Recently felt capable of making decisions about things $j$. Recently been able to enjoy normal day-to-day activities k. Recently been able to face up problems 1 . Recently been feeling reasonably happy, all things considered.

12. Chronic morbidity was recoded as 0 "no" and 1 "yes". Twenty chronic diseases were used to generate variable chronic morbidity which includes Arthritis/rheumatism/Osteoarthritis, Diabetes, Asthma, Chronic lung disease (emphysema, bronchitis, COPD), etc.

13. Disability status was coded as 0 "no" and 1 "yes". Disabilities included disability of vision, hearing, memory, walking, teeth (chewing), and speaking. Full and partial disability was clubbed as 1 "yes" and neither of any was clubbed as 0 "no".

14. The wealth index drawn based on the BKPAI survey is based on the following 30 assets and housing characteristics: household electrification; drinking water source; type of toilet facility; type of house; cooking fuel; house ownership; ownership of a bank or post-office account; and ownership of a mattress, a pressure cooker, a chair, a cot/bed, a table, an electric fan, a radio/transistor, a black and white television, a colour television, a sewing machine, a mobile telephone, any landline phone, a computer, internet facility; a refrigerator, a watch or clock, a bicycle, a motorcycle or scooter, an animaldrawn cart, a car, a water pump, a thresher, and a tractor. The range of index was from poorest to the richest i.e. ranging from lowest to the highest [24]. The five categories of wealth are based in quintile i.e., lowest $20 \%$ to highest $20 \%$ (poorest, poorer, middle, richer and richest).

15. Caste was recoded as Scheduled Tribe, Scheduled Caste, Other Backward Class, and others [30]. The Scheduled Caste include "untouchables"; a group of the population that is socially segregated and financially/economically by their low status as per Hindu caste hierarchy. The Scheduled Castes (SCs) and Scheduled Tribes (STs) are among the most disadvantaged socio-economic groups in India. The $\mathrm{OBC}$ is the group of people who were identified as "educationally, economically and socially backward". The OBC's are considered low in the traditional caste hierarchy but are not considered untouchables. The "other" caste category is identified as having higher social status [30].

16. Religion was recoded as Hindu, Muslim, Sikh, and others

17. Place of residence was coded as urban and rural

18. Data for seven states was available in the data as mentioned in the data section [24].

\section{Statistical analysis}

Descriptive statistics along with percentage distribution were calculated for subjective well-being over 
Table 1 Socio-economic and demographic profile of the study population in India

\begin{tabular}{|c|c|c|}
\hline Background characteristics & Sample & Percentage \\
\hline \multicolumn{3}{|l|}{ Headship status } \\
\hline Nominal & 207 & 4.5 \\
\hline Functional & 4397 & 95.5 \\
\hline \multicolumn{3}{|l|}{ Age group (years) } \\
\hline $60-69$ & 2903 & 63.1 \\
\hline $70-79$ & 1254 & 27.2 \\
\hline $80+$ & 447 & 9.7 \\
\hline \multicolumn{3}{|l|}{ Sex } \\
\hline Male & 3342 & 72.6 \\
\hline Female & 1262 & 27.4 \\
\hline \multicolumn{3}{|l|}{ Educational attainment } \\
\hline Not educated & 1876 & 40.7 \\
\hline 5 years or less & 985 & 21.4 \\
\hline $6-10$ years & 1381 & 30.0 \\
\hline $11+$ years & 362 & 7.9 \\
\hline \multicolumn{3}{|l|}{ Marital status } \\
\hline Not in union & 1670 & 36.3 \\
\hline Currently in union & 2934 & 63.7 \\
\hline \multicolumn{3}{|l|}{ Children co-residing } \\
\hline No & 1381 & 30.0 \\
\hline Yes & 3223 & 70.0 \\
\hline \multicolumn{3}{|l|}{ Working status (last 1 year) } \\
\hline Not working & 2504 & 54.4 \\
\hline Working & 1476 & 32.1 \\
\hline Retired & 624 & 14.6 \\
\hline \multicolumn{3}{|l|}{ Community involvement } \\
\hline No & 837 & 18.2 \\
\hline Yes & 3767 & 81.8 \\
\hline \multicolumn{3}{|l|}{ Trust over someone } \\
\hline No & 788 & 17.1 \\
\hline yes & 3816 & 82.9 \\
\hline \multicolumn{3}{|l|}{ Self-rated health } \\
\hline Good & 2137 & 46.4 \\
\hline Poor & 2467 & 53.6 \\
\hline \multicolumn{3}{|l|}{ Psychological distress } \\
\hline Low & 3667 & 79.6 \\
\hline High & 937 & 20.4 \\
\hline \multicolumn{3}{|l|}{ Chronic morbidity } \\
\hline No & 1748 & 38.0 \\
\hline Yes & 2856 & 62.0 \\
\hline \multicolumn{3}{|l|}{ Disability } \\
\hline No & 1382 & 30.0 \\
\hline Yes & 3222 & 70.0 \\
\hline
\end{tabular}

Wealth status 
Table 1 Socio-economic and demographic profile of the study population in India (Continued)

\begin{tabular}{|c|c|c|}
\hline Background characteristics & Sample & Percentage \\
\hline Poorest & 1066 & 23.2 \\
\hline Poorer & 1005 & 21.8 \\
\hline Middle & 972 & 21.1 \\
\hline Richer & 873 & 19.0 \\
\hline Richest & 686 & 14.9 \\
\hline \multicolumn{3}{|l|}{ Religion } \\
\hline Hindu & 3650 & 79.3 \\
\hline Muslim & 327 & 7.1 \\
\hline Sikh & 423 & 9.2 \\
\hline Others & 203 & 4.4 \\
\hline \multicolumn{3}{|l|}{ Caste } \\
\hline Scheduled Tribe & 981 & 21.3 \\
\hline Scheduled Caste & 225 & 4.9 \\
\hline Other Backward Class & 1726 & 37.5 \\
\hline Others & 1673 & 36.3 \\
\hline \multicolumn{3}{|l|}{ Type of residence } \\
\hline Rural & 3298 & 71.6 \\
\hline Urban & 1306 & 28.4 \\
\hline \multicolumn{3}{|l|}{ State } \\
\hline Himachal Pradesh & 738 & 16.0 \\
\hline Punjab & 649 & 14.1 \\
\hline West Bengal & 584 & 12.7 \\
\hline Orissa & 544 & 11.8 \\
\hline Maharashtra & 660 & 14.3 \\
\hline Kerala & 636 & 13.8 \\
\hline Tamil Nadu & 792 & 17.2 \\
\hline Total & 4604 & 100.0 \\
\hline
\end{tabular}

explanatory variables. Chi-square test [31] was used to find the significance level for the bivariate association between the outcome and the explanatory variables. For finding the association between subjective well-being over explanatory variables binary logistic regression model [32] was used. The outcome variable was subjective well-being coded as "high (0) and low (1)" and the main explanatory variable was headship status coded as "nominal" and "functional".

The equation for logistic distribution is as follows:-

$$
\ln \left(\frac{\pi}{1-\pi}\right)=\beta_{0}+\beta_{1} X_{1}+\beta_{2} X_{2}+\beta_{3} X_{3} \ldots \beta_{n} X_{n}
$$

Where, $\beta_{0}, \ldots ., \beta_{M}$, are the regression coefficients indicating the relative effect of a particular explanatory variable on the outcome. These coefficients change as per the context in the analysis in the study. STATA 14 [33] was used for the analysis purpose.

\section{Results}

Table 1 provides the socio-economic and demographic profile of the Indian older adults included in the analysis. The mean age of the study population was 68 years [CI: $67.8-68.2]$. In the sample, about $5 \%$ of older adults had nominal while $95 \%$ had functional headship status. More than half of the individuals (63\%) belong to the age-group 60-69 years and nearly $10 \%$ were 80 years or older. Three-fourths (73\%) of the older adults were male. Around $41 \%$ of the elderly were uneducated, and $62 \%$ had attained less than primary education. Two-third of the elderly (64\%) were currently in a union and around $70 \%$ were co-residing with their children. One-third of the older adults (32\%) were working, while $15 \%$ were retired at the time of the survey. Nearly $18 \%$ of the elderly reported no community involvement and around $17 \%$ reported that they do not trust someone. The healthrelated factors of the older adults were also included in the analysis. More than half of the elderly (53\%) reported 
Table 2 Percentage of low subjective well-being by background characteristics among older adults in India

\begin{tabular}{lc}
\hline Background characteristics & LSW \\
& (\%)
\end{tabular}

Chi-square $p$-value

Age group (years)

60-69

70-79

26.3

$80+$

33.4

Sex

Male

22.0

Female

30.5

Educational attainment

Not educated

5 years or less

6-10 years

$11+$ years

Marital status

Not in union

Currently in union

Children co-residing

No

Yes

Working status (last 1 year)

Not working

Working

Retired

Community involvement

No

Yes

Trust over someone

No

yes

Self-rated health

Good

Poor

Psychological distress

Low

High

Chronic morbidity

No

Yes

Disability

No

Yes
33.7

25.9

13.7

12.0

30.0

21.1

31.0

20.5

6.7

0.001

0.001

0.001

41.6

20.8

12.4

34.6

60.0

21.0

26.4

14.8

28.4 
Table 2 Percentage of low subjective well-being by background characteristics among older adults in India (Continued)

\begin{tabular}{|c|c|c|}
\hline Background characteristics & $\begin{array}{l}\text { LSWB } \\
\text { (\%) }\end{array}$ & $\begin{array}{l}\text { Chi-square } \\
p \text {-value }\end{array}$ \\
\hline Wealth status & & 0.001 \\
\hline Poorest & 44.7 & \\
\hline Poorer & 31.7 & \\
\hline Middle & 17.4 & \\
\hline Richer & 11.8 & \\
\hline Richest & 7.7 & \\
\hline Religion & & 0.001 \\
\hline Hindu & 26.1 & \\
\hline Muslim & 26.5 & \\
\hline Sikh & 8.8 & \\
\hline Others & 22.4 & \\
\hline Caste & & 0.001 \\
\hline Scheduled Tribe & 31.0 & \\
\hline Scheduled Caste & 28.5 & \\
\hline Other Backward Class & 25.2 & \\
\hline Others & 19.0 & \\
\hline Type of residence & & 0.001 \\
\hline Rural & 25.1 & \\
\hline Urban & 22.5 & \\
\hline State & & 0.001 \\
\hline Himachal Pradesh & 11.0 & \\
\hline Punjab & 9.5 & \\
\hline West Bengal & 47.8 & \\
\hline Orissa & 26.8 & \\
\hline Maharashtra & 33.6 & \\
\hline Kerala & 11.5 & \\
\hline Tamil Nadu & 32.5 & \\
\hline Total & 24.3 & \\
\hline
\end{tabular}

poor health status, and nearly $20 \%$ had a high level of psychological distress. Nearly $62 \%$ of older adults had chronic morbidity, and around $70 \%$ were disabled. According to religion, the majority of respondents were Hindus (80\%). Nearly $72 \%$ of the older adults were rural residents.

\section{Bivariate analysis}

The bivariate analysis of LSWB by various socioeconomic and demographic characteristics is presented in Table 2. The results suggest the significant bivariate associations between LSWB and all the selected background characteristics included in the analysis. The prevalence of LSWB was significantly higher among older adults with nominal headship status (58\%) than functional headship status (23\%). The proportion of older adults with LSWB increases with an increase in age-groups. The prevalence of LSWB was found significantly higher among females, uneducated, separated or widowed, and non-working older adults than their respective counterparts. According to health status, the LSWB was more prevalent among older adults with chronic morbidity, psychological distress, poor self-rated health, and disability. The older adults with the poorest wealth status (45\%) and rural place of residence $(25 \%)$ reported higher LSWB. According to various Indian states, the prevalence of LSWB was reportedly highest in West Bengal (48\%), followed by Maharashtra (34\%) and Tamil Nadu (33\%).

\section{Multivariate analysis}

Table 3 summarises the adjusted odds ratio estimates for low subjective well-being (LSWB) by background characteristics of Indian older adults. After 
Table 3 Logistic regression estimates for low subjective wellbeing by background characteristics among older adults in India

\begin{tabular}{ll}
\hline Background characteristics & LSWB \\
& AOR $(95 \% \mathrm{Cl})$ \\
\hline
\end{tabular}

\section{Headship status}

Nominal

Functional

\section{Age group (years)}

60-69

70-79

$80+$

Sex

Male

Female

\section{Educational attainment}

Not educated

5 years or less

6-10 years

$11+$ years

\section{Marital status}

Not in union

Currently in union

\section{Children co-residing}

No

Yes

Working status (last 1 year)

Not working

Working

Retired

\section{Community involvement}

No

Yes

\section{Trust over someone}

No

yes

Self-rated health

Good

Poor

\section{Psychological distress}

Low

High

Chronic morbidity

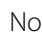

Yes

\section{Disability}

$1.59 *(1.10,2.31)$

Ref.

Ref.

$1.05(0.87,1.28)$

$1.34 *(1.01,1.79)$

Ref.

$0.95(0.70,1.27)$

$1.83 *(1.2,2.78)$

$1.71 *(1.13,2.59)$

$1.15(0.77,1.71)$

Ref.

Ref.

$0.99(0.75,1.3)$

Ref.

$1.00(0.82,1.21)$

$1.30 *(1.06,1.61)$

Ref.

$0.770 .53,1.12)$

$1.49 *(1.20,1.84)$

Ref.

$1.72^{*}(1.38,2.15)$

Ref.

$2.09^{*}(1.73,2.52)$

Ref.

$5.60 *(4.64,6.76)$

Ref.

$1.21 *(1.00,1.47)$

Ref.
Table 3 Logistic regression estimates for low subjective wellbeing by background characteristics among older adults in India (Continued)

\begin{tabular}{|c|c|}
\hline Background characteristics & $\begin{array}{l}\text { LSWB } \\
\text { AOR }(95 \% \mathrm{Cl})\end{array}$ \\
\hline Yes & $1.60 *(1.28,1.99)$ \\
\hline \multicolumn{2}{|l|}{ Wealth status } \\
\hline Poorest & $3.13^{*}(2.14,4.58)$ \\
\hline Poorer & $2.34^{*}(1.66,3.32)$ \\
\hline Middle & $1.71 *(1.22,2.39)$ \\
\hline Richer & $1.45^{*}(1.03,2.03)$ \\
\hline Richest & Ref. \\
\hline \multicolumn{2}{|l|}{ Religion } \\
\hline Hindu & Ref. \\
\hline Muslim & $1.18(0.85,1.64)$ \\
\hline Sikh & $0.87(0.50,1.52)$ \\
\hline Others & $1.14(0.73,1.77)$ \\
\hline \multicolumn{2}{|l|}{ Caste } \\
\hline Scheduled Tribe & Ref. \\
\hline Scheduled Caste & $0.84(0.55,1.27)$ \\
\hline Other Backward Class & $1.00(0.78,1.28)$ \\
\hline Others & $0.92(0.72,1.17)$ \\
\hline \multicolumn{2}{|l|}{ Type of residence } \\
\hline Rural & Ref. \\
\hline Urban & $1.39 *(1.15,1.69)$ \\
\hline
\end{tabular}

controlling for various other variables, older adults with nominal headship status were 1.59 times significantly more likely to have LSWB than individuals with functional headship status $(\mathrm{OR}=1.59 ; 95 \% \mathrm{CI}$ : $1.10,2.31)$. The individuals aged 80 years and above had $34 \%$ significantly higher odds of having LSWB compared to the individuals belonging to the age group 60 to 69 years $(\mathrm{OR}=1.34 ; 95 \% \mathrm{CI}: 1.01,1.79)$. According to educational attainment, older adults with no or less than the primary level of education had significantly higher odds of having LSWB than those with more than 11 years of education. We did not find any association between marital status and LSWB among older adults. Results further showed that the LSWB among older adults is not associated with their status of living with children. Nonworking older adults were found to have $30 \%$ significantly higher odds of LSWB than working older adults $(\mathrm{OR}=1.30 ; 95 \% \mathrm{CI}: 1.06,1.61)$.

Older adults with psychological distress, chronic morbidity, poor self-reported health, no community involvement and no one trust to on were at comparatively higher risk of LSWB than their counterparts. 
Table 4 Logistic regression estimates for low subjective wellbeing by sex among older adults in India

\begin{tabular}{lll}
\hline $\begin{array}{l}\text { Background } \\
\text { characteristics }\end{array}$ & $\begin{array}{l}\text { LSWB } \\
\text { AOR }(95 \% \mathrm{Cl})\end{array}$ & Female \\
\cline { 2 - 3 } & Male & \\
\hline Headship status & & $1.69^{*}(1.03-2.79)$ \\
Nominal & $1.60^{*}(1.33-2.93)$ & Ref. \\
\hline
\end{tabular}

The analysis was controlled for the other factors that were presented in table3; Additionally, the analysis is controlled for states; Ref Reference, $A O R$

Adjusted Odds ratio, $\mathrm{Cl}$ Confidence interval *if $p<0.05$

According to the wealth index, the odds of having LSBW increases with a decline in wealth index; for instance, the older adults in the poorest category do have almost three times significantly higher odds of having LSBW compared to older adults in the richest category $(\mathrm{OR}=3.13 ; 95 \% \mathrm{CI}: 2.14,4.58)$. The older adults' who resided in the urban area had nearly $39 \%$ significantly higher likelihood of having LSWB compared to their rural counterparts $(\mathrm{OR}=1.39 ; 95 \% \mathrm{CI}$ : $1.15,1.69)$. We did not find any association of LSWB with religion and caste.

Table 4 represents the stratified analysis by gender. It was found that older males who were nominal heads had a $60 \%$ significantly higher likelihood to suffer from LSWB than the older males who were functional heads [AOR: 1.60; 95\% CI: 1.33-2.93]. Similarly, older females who were nominal head had a $69 \%$ significantly higher likelihood to suffer from LSWB than the older females who were functional head [AOR: 1.69; $95 \%$ CI: $1.03-$ 2.79].

\section{Discussion}

In order to determine the major factors associated with the level of subjective well-being of older individuals especially their actual headship status, a binary logistic regression was employed and it has shown statistically significant associations. Older people after a certain age consider themselves as physically aged and mentally withdraw from the roles and responsibilities they feel they are unable to perform [19]. Such a withdrawal itself reinforces the feelings of sickness and weakness and results in a decline in their overall well-being [16]. Consistently, the older adults who were nominal heads with no role in household decision making in the current study were more likely to report lower levels of subjective wellbeing. This finding suggests that policies and interventions can create more opportunities for meaningful engagement of older individuals and establish a more age-friendly household environment with an ultimate goal of promoting their late-life wellbeing. Also, the older parents should be enabled to become more actively involved in household activities and strengthen the intergenerational relationships.

Other findings of the present study suggest that several socio-demographic factors including age, level of education, community involvement, and trust were significant predictors of subjective well-being in old age. Age was found a significant predictor of subjective wellbeing among older Indian adults and it shows that with increasing age, subjective well-being will decrease. On the whole, the finding is consistent with and supports current wellbeing literature [34-36]. A possible explanation for the negative effects of age on subjective wellbeing may be the result of life stresses, such as widowhood, poor health condition, the decline in social and family roles, and decline in social engagement. Consistent with previous studies, older adults who were involved in community activities or had trust in someone reported a higher level of subjective well-being than their counterparts [28]. It is believed that social support is a powerful source of emotional wellbeing that results in higher levels of overall well-being especially in traditional societies [37, 38]. Similarly, older people who are socially active have a better chance of benefiting from interpersonal relationships and suffer less from loneliness $[39,40]$. While being in a marital union was significantly associated with subjective well-being at a bivariate level, it was not a predictor in the multivariable analyses.

Education has always been hailed as an essential factor of wellbeing in late life. It has been linked with better opportunities, better health, and a high standard of living [41]. Also, a vast proportion of the older Indian adults is uneducated and thereby unskilled and is mostly engaged in the unorganized sector leading to higher dependency on their children at old age and to a lower status [42]. The same is reflected in the current regression results where the likelihood of low well-being increases with a decrease in educational status. Illiterates and older individuals with primary schooling are likely to be of low well-being with reference to highly educated and it is statistically significant. The finding suggests the importance of higher education that leads to better awareness as well as better economic opportunities thereby ensuring higher levels of well-being in older ages [43]. The implications are particularly relevant in an Indian sociocultural setting where people are oftentimes classified as old in relation to their inability to perform roles and responsibilities [16].

The positive association of psychological distress with LSWB observed in our study can be explained as the psychological distress may reflect the differences in health conditions and issues of access to resources and mental health care [44]. As evidence suggests physical health status plays a preponderant role in late-life wellbeing [45-47]. Consistently, the present study found a 
significant positive association of poor self-rated health and prevalence of chronic morbidity with LSWB. The finding that disability had a significant positive association with LSWB was in concordance with earlier studies that highlighted functional activities namely, activities of daily living (ADLs), instrumental ADLs as predictors of subjective well-being in later years of life $[17,18]$. This also supports the findings that reduced physical functionality among older adults is related to poor mental wellbeing $[48,49]$.

In addition, household wealth status appeared to be an important factor associated with subjective well-being among older Indian adults. This finding is consistent with some previous studies which have found that household economic status is a significant predictor of quality of life and psychological well-being [50-52]. Also it supports the notion that people from higher wealth quintiles can easily satisfy their basic needs such as food, housing, and health; therefore, a higher level of well-being is attained. Finally, several studies have found rural-urban differences in terms of psychological well-being, quality of life, life satisfaction, depression, happiness, and mental health among elderly people $[53,54]$. The finding of our study that indicated that urban place of residence as a positive factor of subjective wellbeing in old age can be explained by the differentials in rural-urban lifestyles and the highly available social networks in urban areas.

As with any study, there are several limitations to this study to be acknowledged. The first is the crosssectional nature of this study which prevents the possibility of drawing conclusions about causal relationships between the variables studied. Second, although this study had a large sample size, since it was carried out among older individuals in seven states of India, there should be caution while results being generalized to the older population across the country.

\section{Conclusion}

Policy makers should pay special attention to the vulnerable groups of older population and promote interventions according to their needs. In addition, older adults who do not have a household headship with power with active participation in decision making as well as those who have no involvement in social activities or have poor health conditions need to be given more attention. Thus, to keep a large proportion of older population gainfully engaged, their care and support should be ensured via providing appropriate services that would enhance their roles and responsibilities and overall wellbeing.

\section{Abbreviations}

LSWB: Low Subjective well-being; Cl: Confidence interval; AOR: Adjusted Odds ratio; UNFPA: United Nation's Population Fund; BKPAl: Building a Knowledge Base on Population Aging in India; PSU: Primary sampling unit

\section{Acknowledgements}

Not applicable.

\section{Authors' contributions}

Conceived and designed the research paper: SS and SKS; analysed the data: SS; Contributed agents/materials/analysis tools: MT and MK; Wrote the manuscript: MT, SS, SKS and MK; Refined the manuscript: SS and MT. The author(s) read and approved the final manuscript.

\section{Funding}

Authors did not receive any funding to carry out this research.

\section{Availability of data and materials}

The study utilizes a secondary data which is available only on request from director@isec.ac.in or india.office@unfpa.org.

\section{Declarations}

Ethics approval and consent to participate

Ethical approval for the data has been obtained from the Ethics Committee in the University of Southampton. Informed written consent was obtained from each participant, who were ensured that data would remain confidential and used for research purposes only. All methods were carried out in accordance with relevant guidelines and regulations.

\section{Consent for publication}

Not applicable.

\section{Competing interests}

The authors declare that they have no competing interests.

\section{Author details}

${ }^{1}$ Department of Mathematical Demography and Statistics, International Institute for Population Sciences, Mumbai, Maharashtra 400088, India.

${ }^{2}$ Department of Population Policies and Programs, International Institute for Population Sciences, Mumbai, Maharashtra 400088, India.

Received: 23 February 2021 Accepted: 30 April 2021

Published online: 12 May 2021

\section{References}

1. Chandramouli C. Census of India 2011: a story of innovations; 2012. http:// www.censusindia.gov.in. Accessed 24 Oct 2020.

2. United Nations. Addressing the Challenges of Population Ageing in Asia and the Pacific: Implementation of the Madrid international plan of action on ageing. 2018. Epub ahead of print 2018. DOl: https://doi.org/10.18356/32 056b9e-en, 2017.

3. Boyle $\mathrm{G}$. The role of autonomy in explaining mental ill-health and depression among older people in long-term care settings. Ageing Soc. 2005:25(5):731-48. https://doi.org/10.1017/S0144686X05003703.

4. Sudha S, Suchindran C. Marital Status, Family Ties, and Self-rated Health Among Elders In South India. J Cross Cult Gerontol. Epub ahead of print 2007. DOl: https://doi.org/10.1007/s10823-006-9027-x.

5. Bhat AK, Dhruvarajan RAJ, Bhat AK. Ageing in India : drifting intergenerational relations, challenges and options. Ageing Soc. 2001;21(5): 621-40. https://doi.org/10.1017/S0144686X0100842X.

6. Bansod DW. Status, decision-making role and expectations of older persons in rural Maharashtra, India. Asia-Pacific Popul J. 2011;26:3-19.

7. Ladusingh L, Narayana MR. The role of familial transfers in supporting the lifecycle deficit in India. In: Population Aging and the Generational Economy; 2011.

8. van Willigen J, Chadha NK, Kedia S. Personal networks and sacred texts: social aging in Delhi, India. J Cross Cult Gerontol. 1995;10(3):175-98. https:// doi.org/10.1007/BF00972239.

9. Vera-sanso P. They Don't need it, and I Can't give it: filial support in South India. Age Child Eur Asian Perspect. 2004:77-105.

10. Bojorquez-Chapela I, Manrique-Espinoza BS, Mejía-Arango S, Solís MMTR, Salinas-Rodríguez A. Effect of social capital and personal autonomy on the incidence of depressive symptoms in the elderly: evidence from a longitudinal study in Mexico. Aging Ment Heal. 2012;16(4):462-71. https:// doi.org/10.1080/13607863.2011.651432. 
11. Duraisamy P. Morbidity in Tamil Levels, Differentials and Determinants. Econ Polit Weekely. 1998;33:982-90.

12. Gupta I, Dasgupta P, Sawhney M. Health of the Elderly in India Some Aspects of Vulnerability; 2001. p. 1-23.

13. Das B, Sengupta R, Paul K. Regional variation and determinants of wellbeing of the elderly in India. J Popul Soc Stud. 2018;26(3):219-34. https:// doi.org/10.25133/JPSSv26n3.016.

14. Muhammad T, Srivastava S. Why Rotational Living Is Bad for Older Adults ? Evidence from a Cross- Sectional Study in India. J Popul Ageing. 2020;1. Epub ahead of print. https://doi.org/10.1007/s12062-020-09312-4.

15. Lamb S. The making and unmaking of persons: notes on aging and gender in North India. Ethos. 1997;25(3):279-302. https://doi.org/10.1525/eth.1997.2 5.3.279.

16. Ladusingh L, Ngangbam S. Domains and Determinants of Well-Being of Older Adults in India. J Cross Cult Gerontol Epub ahead of print. 2016;31(1): 89-111. https://doi.org/10.1007/s10823-016-9279-z.

17. Von Humboldt S, Leal I, Pimenta F. Sense of coherence, sociodemographic, lifestyle, and health-related factors in older adults' subjective well-being. Int J Gerontol. 2015;9(1):15-9. https://doi.org/10.1016/j.ijge.2014.01.007.

18. Witsø $A E$, Eide $A H$, Vik K. Older homecare service recipients' satisfaction with participation in daily life activities. Phys Occup Ther Geriatr. 2012;30(2):85101. https://doi.org/10.3109/02703181.2012.678970.

19. Vera-Sanso P. Experiences in old age: a south Indian example of how functional age is socially structured. Oxford Dev Stud. 2006;34:246-9.

20. Posel DR. Who are the heads of household, what do they do, and is the concept of headship useful? An analysis of headship in South Africa. Dev South Afr. 2001;18(5):651-70. https://doi.org/10.1080/03768350120097487.

21. Charles S, Carstensen L. Social and emotional aging. Annu Rev Psychol. 2010;61(1):383-409. https://doi.org/10.1146/annurev.psych.093008.100448.

22. Reitzes DC, Mutran EJ. Self-concept as the Organization of Roles: importance, centrality, and balance. Sociol Q. 2002;43(4):647-67. https://doi. org/10.1111/j.1533-8525.2002.tb00070.x.

23. United Nations, Department of Economic and Social Affairs, Population Division. World population prospects 2019: ten key findings. 2019.

24. UNFPA. Report on the Status of Elderly in Select States of India; 2011. p. 2011.

25. Srivastava S, Muhammad T. Violence and associated health outcomes among older adults in India: A gendered perspective. SSM - Popul Heal.12. Epub ahead of print 1 December 2020. DOl: https://doi.org/10.1016/j. ssmph.2020.100702.

26. Srivastava S, Muhammad T. In Pursuit of Happiness: Changes in Living Arrangement and Subjective Well-Being among Older Adults in India. J Popul Ageing. Epub ahead of print 2021. DOl: https://doi.org/10.1007/s12 062-021-09327-5.

27. Patel R, Marbaniang SP, Srivastava S, et al. Gender differential in low psychological health and low subjective well-being among older adults in India: With special focus on childless older adults; 2021. p. 1-16.

28. Srivastava S, Chauhan S, Muhammad T, Simon DJ, Kumar P, Patel R, et al. Older adults ' psychological and subjective well-being as a function of household decision making role : evidence from cross-sectional survey. Clin Epidemiol Glob Heal. 2021;10:100676. https://doi.org/10.1016/j.cegh.2020.1 00676.

29. Srivastava S, Chauhan S, Patel R. Socio-economic inequalities in the prevalence of poor self-rated health among older adults in India from 2004 to 2014: a decomposition analysis. Ageing Int. 2021;46:182-99. https://doi. org/10.1007/s12126-020-09385-8

30. Srivastava, S., Kumar, S. Does socio-economic inequality exist in micronutrients supplementation among children aged 6-59 months in India? Evidence from National Family Health Survey 2005-06 and 2015-16. BMC Public Health. 2021;21:545. https://doi.org/10.1186/s12889-021-10601-6.

31. Mchugh ML. The chi-square test of independence lessons in biostatistics. Biochem Medica.

32. King JE. Binary Logistic Regression. Best Practices in Quantitative Methods. Edited by: Osborne, Jason SAGE Publications, Inc., 2008. pp. 358-384. SAGE Research Methods. 6 May 2021. https://doi.org/10.4135/9781412995627.

33. StataCorp. Stata: Release 14. Statistical Software. 2015.

34. Blanchflower DG. Is happiness U-shaped everywhere? Age and subjective well-being in 145 countries. J Popul Econ. 2021;34(2):575-624. https://doi. org/10.1007/s00148-020-00797-z.

35. Hansen T, Slagsvold B. The age and subjective well-being paradox revisited: a multidimensional perspective. Nor Epidemiol. 2012;22:187-95.
36. Mantovani EP, Lucca SR, Neri AL. Associations between meanings of old age and subjective well-being indicated by satisfaction among the elderly. Rev Bras Geriatr Gerontol. 2016;19(2):203-22. https://doi.org/10.1590/180998232016019.150041

37. Appau S, Awaworyi Churchill S, Smyth R, Zhang Q Social Capital Inequality and Subjective Wellbeing of Older Chinese Soc Indic Res. Epub ahead of print 2020. DOI: https://doi.org/10.1007/s11205-020-02340-9.

38. Muhammad T, Balachandran A, Srivastava S. Socio-economic and health determinants of preference for separate living among older adults: a crosssectional study in India. PLoS One. 2021;16:1-14.

39. Martínez LM, Estrada D, Prada SI. Mental health, interpersonal trust and subjective well-being in a high violence context. SSM - Popul Heal. 2019;8: 100423. https://doi.org/10.1016/j.ssmph.2019.100423.

40. Freedman VA, Stafford F, Schwarz N, Conrad F, Cornman JC. Disability, participation, and subjective wellbeing among older couples. Soc Sci Med 2012;74(4):588-96. https://doi.org/10.1016/j.socscimed.2011.10.018.

41. Okun MA, Stock WA, Covey RE. Assessing the effects of older adult education on subjective well-being. Educ Gerontol. 1982;8(6):523-36. https://doi.org/10.1080/0360127820080601.

42. Irudaya RS, Mishra US, Sarma PS. Health concerns among India's elderly. Int J Aging Hum Dev. 2001;53:181-94.

43. Yakovlev $\mathrm{P}$, Leguizamon S. Ignorance is not bliss: on the role of education in subjective well-being. J Socio Econ. 2012;41(6):806-15. https://doi.org/1 0.1016/j.socec.2012.08.009.

44. He W, Muenchrath MN, Kowal PR. Shades of gray: a cross-country study of health and well-being of the older populations in SAGE countries, 20072010. US Census Bur. 2012:2007-10.

45. Angner E, Ghandhi J, Williams Purvis K, Amante D, Allison J. Daily functioning, health status, and happiness in older adults. J Happiness Stud. 2013;14(5):1563-74. https://doi.org/10.1007/s10902-012-9395-6.

46. Tomaszewski W. Living Environment, Social Participation and Wellbeing in Older Age: The Relevance of Housing and Local Area Disadvantage. 2013;6, 1-2, 119, 156. Epub ahead of print 2013. DOI: https://doi.org/10.1007/s12 062-012-9077-5

47. Srivastava S, Purkayastha N, Chaurasia H, et al. Socioeconomic inequality in psychological distress among older adults in India : a decomposition analysis. BMC Psychiatry. 2021;21:1-15.

48. Bhandari P, Paswan B. Lifestyle Behaviours and Mental Health Outcomes of Elderly: Modification of Socio-Economic and Physical Health Effects. Ageing Int. Epub ahead of print 2020. DOl: https://doi.org/10.1007/s12126-020-093 71-0.

49. Muhammad T, Govindu M, Srivastava S. Relationship between chewing tobacco, smoking, consuming alcohol and cognitive impairment among older adults in India: a cross-sectional study. BMC Geriatr. 2021;21(1):85. https://doi.org/10.1186/s12877-021-02027-x

50. Diener E, Biswas-Diener R. Will money increase subjective well-being? Soc Indic Res. 2002;57:509-16.

51. Zhou Y, Zhou L, Fu C, et al. Socio-economic factors related with the subjective well-being of the rural elderly people living independently in China. Int J Equity Health. 2015:14:1-9.

52. Howell RT, Howell CJ. The relation of economic status to subjective wellbeing in developing countries: a meta-analysis. Psychol Bull. 2008;134(4): 536-60. https://doi.org/10.1037/0033-2909.134.4.536.

53. Tobiasz-Adamczyk B, Zawisza K. Urban-rural differences in social capital in relation to self-rated health and subjective well-being in older residents of six regions in Poland. Ann Agric Environ Med. 2017;24(2):162-70. https://doi. org/10.26444/aaem/74719.

54. Liu Y, Dijst M, Faber J, Geertman S, Cui C. Healthy urban living: residential environment and health of older adults in Shanghai. Heal Place. 2017;47:809. https://doi.org/10.1016/j.healthplace.2017.07.007.

\section{Publisher's Note}

Springer Nature remains neutral with regard to jurisdictional claims in published maps and institutional affiliations. 